\title{
Charge Transport in DNA Duplex/Quadruplex Conjugates
}

Sarah Delaney and Jacqueline K. Barton

Supporting Information for World Wide Web Edition 


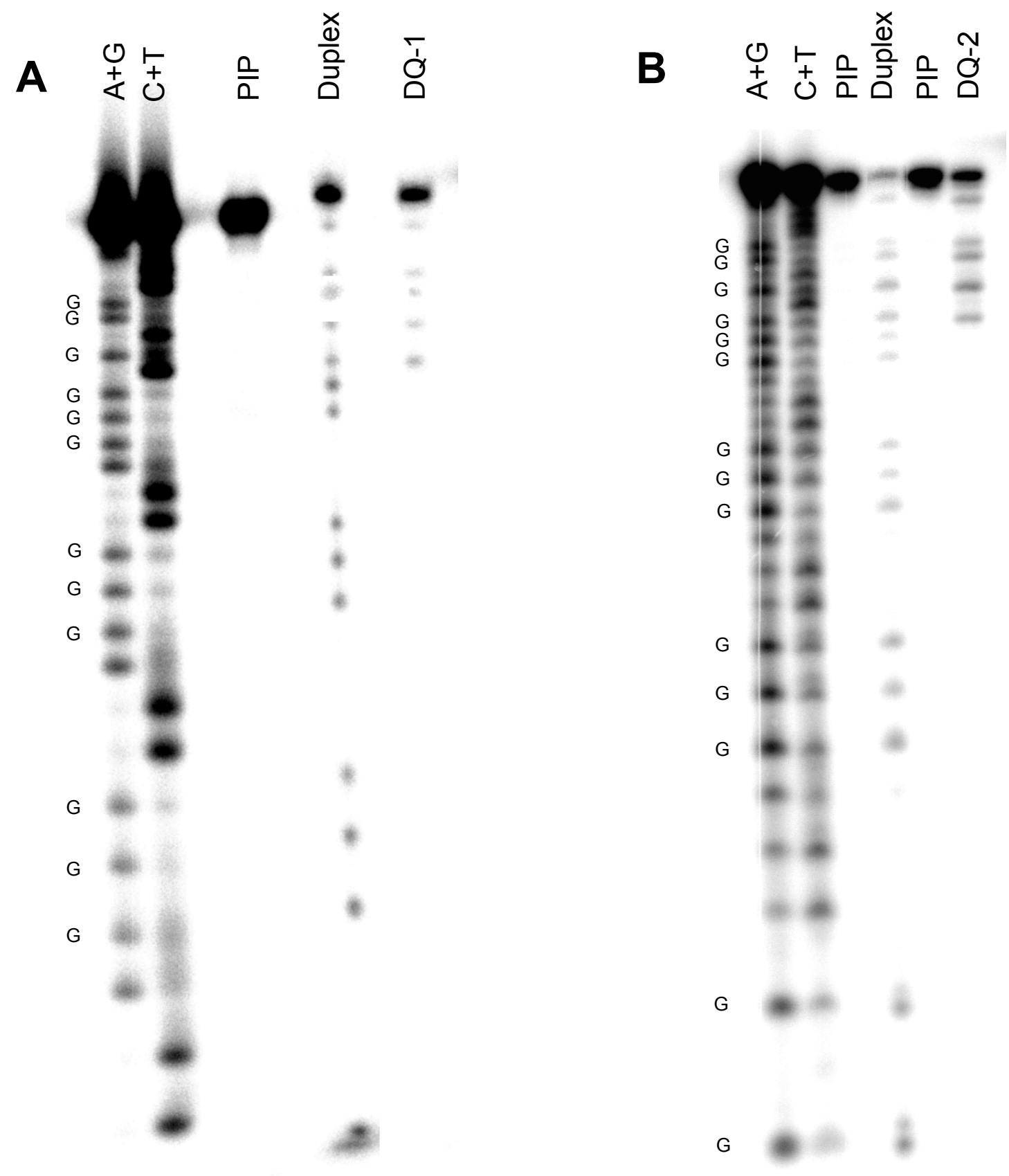

S1. DMS methylation protection analysis of A) DQ-1 and B) DQ-2 along with duplex controls. Maxam-Gilbert sequencing reactions $\mathrm{A}+\mathrm{G}$ and $\mathrm{C}+\mathrm{T}$ are shown in lanes 1 and 2 , respectively. Damage of duplex/quadruplex conjugates treated with piperidine, but not DMS, is shown in lanes labeled PIP. Methylation of the 32 base pair duplex control is shown in lanes labeled Duplex. Damage of duplex/quadruplex conjugates following treatment with DMS and piperdine are shown in lanes $D Q-1$ and $D Q-2$. The duplex and conjugate concentrations were 4 _ in $10 \mathrm{mM}$ potassium phosphate, $\mathrm{pH} 7$ with $100 \mathrm{mM} \mathrm{KCl}$. 


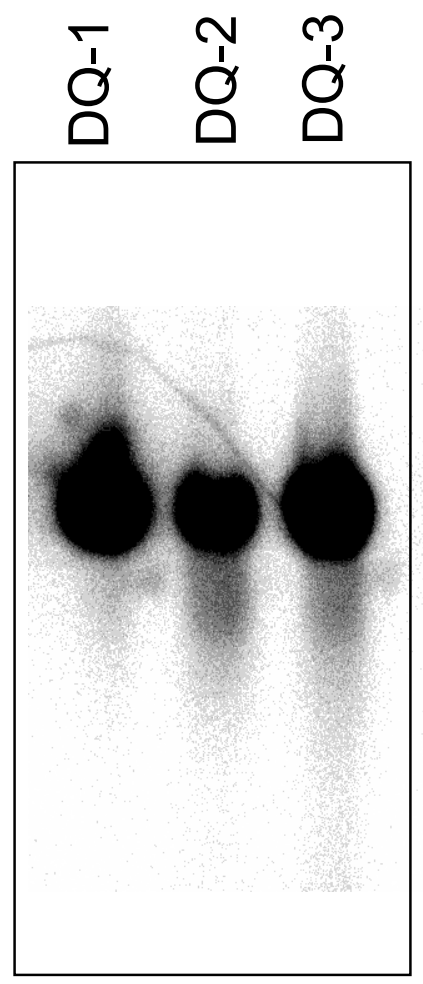

S2. Native gel electrophoresis of DQ-1, DQ-2, and DQ-3. Conjugates were annealed at a concentration of $4 \square \mathrm{M}$ in $10 \mathrm{mM}$ potassium phosphate, $\mathrm{pH} 7$ with $100 \mathrm{mM} \mathrm{KCl}$. Samples were electrophoresed at $4{ }^{\circ} \mathrm{C}$ and $10 \mathrm{~W}$ for $\sim 12$ hours through a $12 \%$ nondenaturing gel containing $100 \mathrm{mM} \mathrm{KCl}$ in the gel matrix, running buffer $(0.5 \mathrm{X} \mathrm{TBE})$, and loading dye.
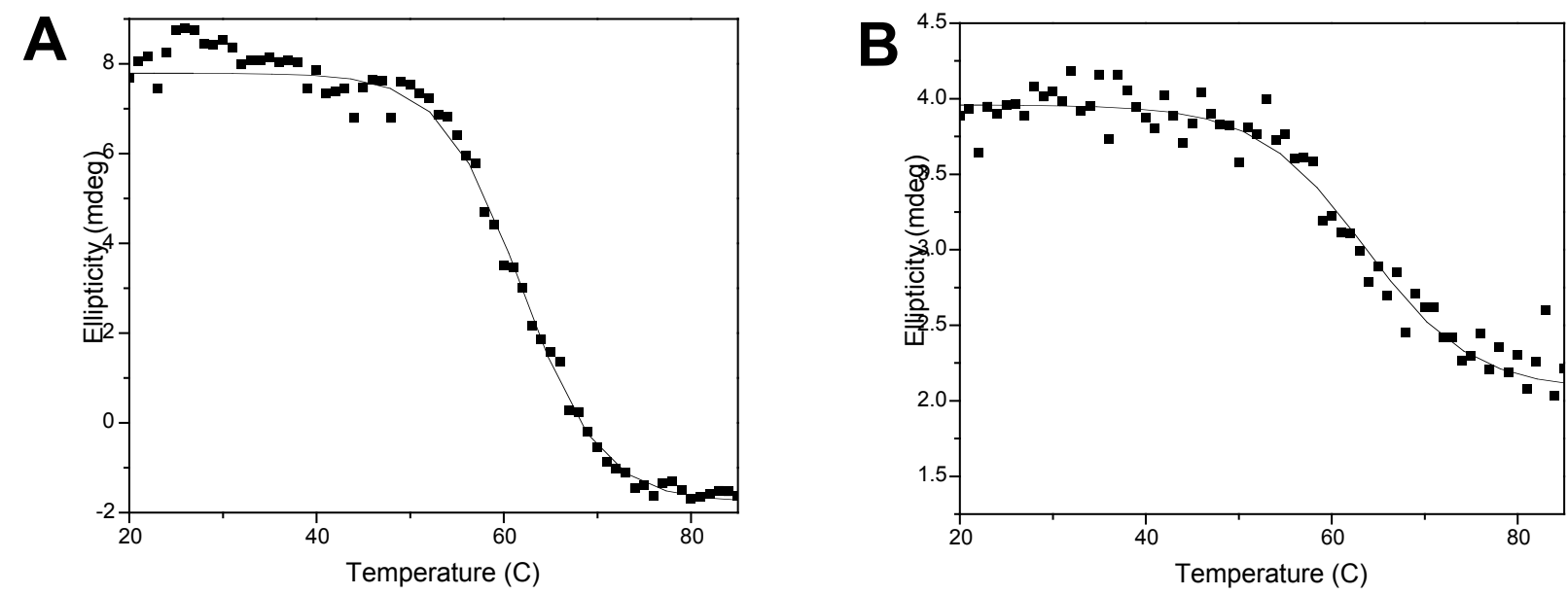

S3. CD melting temperature profile of A) the quadruplex forming strand of DQ-1 (4 B) duplex alone (4_M) monitored at $285 \mathrm{~nm}$, in $10 \mathrm{mM}$ potassium phosphate, $\mathrm{pH} 7$ with 100 $\mathrm{mM} \mathrm{KCl}$. 


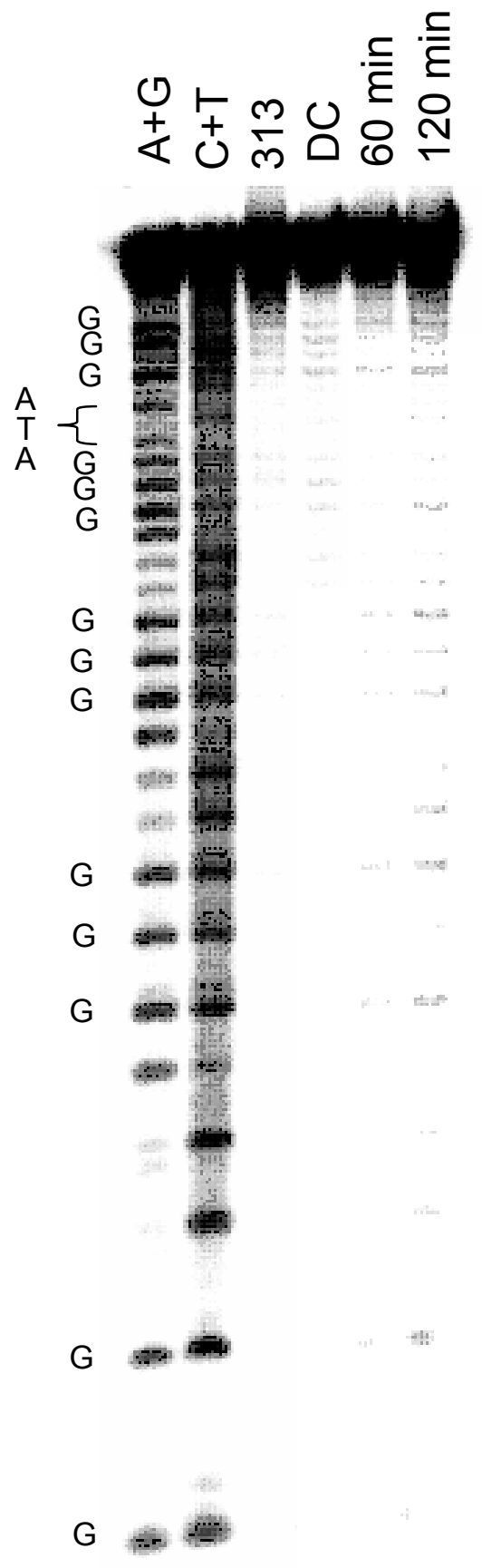

S4. PAGE of duplex/quadruplex conjugate with an ATA linker between duplex and quadruplex regions. Maxam-Gilbert sequencing reactions $\mathrm{A}+\mathrm{G}$ and $\mathrm{C}+\mathrm{T}$ are shown in lanes 1 and 2, respectively. Lane 3 shows the photocleavage of the rhodium intercalator after irradiation at 313 $\mathrm{nm}$ for $30 \mathrm{~min}$. Lanes 4-6 display the oxidative damage after irradiation at $365 \mathrm{~nm}$ for 0 , 60, and $120 \mathrm{~min}$, respectively. Conjugate concentration was $4 \square \mathrm{M}$ in $10 \mathrm{mM}$ potassium phosphate, $\mathrm{pH} 7$ with $100 \mathrm{mM} \mathrm{KCl}$. 